\title{
MUERTE EMBRIONARIA TEMPRANA: ¿TIENE INFLUENCIA EL FACTOR MASCULINO?
}

\author{
Aura María Gil Villa, Wálter Darío Cardona-Maya y Ángela Patricia Cadavid Jaramillo.
}

Grupo Reproducción. Sede de Investigación Universitaria (SIU). Universidad de Antioquia. Medellín. Colombia.

Resumen.- OBJETIVO: Discutir el efecto que puede tener el factor masculino sobre la muerte embrionaria temprana.

MÉTODO: Se hace una revisión de literatura de diferentes componentes del espermatozoide que pueden tener algún papel en la muerte embrionaria temprana.

RESULTADOS: Antes que ocurra la fusión entre la membrana plasmática del espermatozoide y la del oocito, ambos gametos deben sufrir un proceso de maduración que permita la fecundación y el desarrollo embrionario exitosos. El estudio de las parejas con muerte embrionaria temprana, usualmente se aborda desde el factor femenino por la obvia relación de la mujer con su producto en desarrollo, pero no es ilógico suponer que una alteración genética o epigenética en el espermatozoide, tenga un papel importante en estas pérdidas por su importancia en el desarrollo placentario y embrionario. El espermatozoide posee algunas características como el empaquetamiento del ADN, la apoptosis y los antioxidantes en el plasma seminal, que protegen la integridad estructural y funcional de la célula germinal, permitiendo que el espermatozoide fecunde al oocito y contribuya al desarrollo embrionario. Sin embargo, alteraciones epigenéticas como el remodelamiento de la cromatina y la consecuente perturbación de los eventos relacionados con la impronta genómica podrían ser causas de origen paterno que pueden tener alguna representación en las muertes embrionarias tempranas como también lo son la ausencia o alteración del centrosoma, el acortamiento telomérico y la ausencia de RNA espermático.

CONCLUSIONES: El conocimiento de la intervención espermática en el desarrollo embrionario proporcionará bases para el entendimiento y el posible diagnóstico y tratamiento de diversas alteraciones reproductivas masculinas que puedan estar ocasionando fallas en el desarrollo posterior del embrión.

Palabras clave: Oocito. Espermatozoide. Impronta. Fecundación. Muerte embrionaria.

Summary.- OBJECTIVE: To discuss the possible role of the male factor in early embryo death.

METHOD: A detailed bibliographic review has been put together to establish which alterations in spermatozoa can be associated with early embryo death.

RESULTS: Before the fusion between plasma membranes of the sperm and the oocyte occurs, both germ cells must 
undergo a maturation process that allows successful fertilization and embryo development. The study of couples with early embryo loss is usually approached from the side of the woman due to the obvious relationship that exists between the female and the developing embryo. However, it is not illogical to suppose that a genetic or epigenetic alteration of the sperm could have important consequences on these losses due to the necessary contribution of the male gamete not only to embryonic but also to placental development. On the other hand, spermatozoa have certain characteristics such as a highly compact DNA, they undergo apoptosis and the seminal plasma contains antioxidants that protect the structural and functional integrity of the germ cell. These factors assure fertilization and embryo development. Nevertheless, epigenetic alterations of the sperm such as altered chromatin packing, mistakes in imprinting, absence or alteration of the centrosome, telomeric shortening and absence of sperm RNA, could affect functions leading to early embryo loss.

CONCLUSIONS: Knowledge concerning sperm intervention previous to embryo development will provide the basis for better understanding and for possible diagnosis and treatment of diverse reproductive alterations in men that could impede embryo development.

Keywords: Oocyte. Spermatozoa. Imprinting. Fertilization. Embryo loss.

\section{INTRODUCCIÓN}

La pérdida del producto de la gestación es una complicación que afecta del 15 al $20 \%$ de los embarazos clínicamente diagnosticados en mujeres en edad reproductiva. Se han descrito diferentes causas de muerte embrionaria temprana como genéticas, anatómicas, endocrinas, inmunológicas, microbiológicas, trombóticas, sicológicas e iatrogénicas, pero persiste más del $50 \%$ de causa idiopática (1). El estudio de las parejas con muerte embrionaria temprana, usualmente se aborda desde el factor femenino por la obvia relación de la mujer con su producto en desarrollo, pero poco se tienen en cuenta los factores paternos como causa de pérdida o alteración del embarazo. En los protocolos de estudio de las parejas con aborto recurrente, escasamente se consideran las alteraciones cromosómicas, principalmente las translocaciones balanceadas, como posible causa de origen paterno y para esto se ordena un cariotipo en células de sangre periférica.

Por su parte, el factor masculino, particularmente el estudio de los parámetros seminales, sí se estudia en las parejas que consultan por infertilidad y se calcula que un $50 \%$ de las causas puede ser por alteraciones espermáticas (2). Diversas variaciones en las células espermáticas podrían conducir a fallas reproductivas en el hombre que abarcan una amplia gama que va desde la incapacidad para fecundar, hasta malformaciones que pueda presentar el recién nacido atribuibles a factores paternos; por esto no es ilógico suponer que un daño en el gameto masculino pueda tener un papel significativo en las pérdidas tempranas.

Tradicionalmente, se ha considerado que el espermatozoide es sólo el vehículo que entrega el complemento genético paterno al oocito $(3,4)$ pero también los mecanismos epigenéticos del espermatozoide contribuyen en la formación de un nuevo individuo al regular la expresión de genes, proteínas y estructuras necesarias para el desarrollo placentario y embrionario (5-7). A pesar que el espermatozoide puede estar sometido a diferentes condiciones externas que pueden alterar su integridad estructural y funcional durante su maduración y desplazamiento por ambos tractos reproductivos, también posee algunas características que lo protegen de este daño como son empaquetamiento del ADN, apoptosis y antioxidantes en el plasma seminal, las cuales permiten que el espermatozoide fecunde al oocito y contribuya al desarrollo embrionario (8); sin embargo, se ha sugerido que la alteración en el remodelamiento de la cromatina (9) y la consecuente perturbación de los eventos relacionados con la impronta genómica (7) podrían ser causas de origen paterno que pueden tener algún papel en las muertes embrionarias tempranas como también lo son la ausencia o alteración del centrosoma (10), el acortamiento telomérico (11) y la ausencia de RNA espermático (6).

Antes que ocurra la fusión del espermatozoide con la membrana plasmática del oocito, ambos gametos deben haber sufrido un proceso de maduración que permite la fecundación y el desarrollo embrionario exitosos $(12,13)$. A continuación se describirá con más detalle estos eventos para poder entender con mayor propiedad la importancia que tienen la integridad estructural y funcional no sólo del oocito sino también del espermatozoide en el desarrollo embrionario y cómo las alteraciones en el gameto masculino podrían llevar a la muerte embrionaria temprana que es el objetivo principal de esta revisión.

\section{Maduración del oocito}

En la maduración del oocito, las vías de cmos (protooncogen mos) y MAP quinasa (proteína activada por mitógeno) regulan la formación del huso meiótico que se inicia en el centro y migra, a lo largo del eje longitudinal, hacia la periferia del oocito, asegurando que muy poco citoplasma se pierda 
cuando ocurra la primera división de reducción (14). Finalmente, la meiosis procede y el primer cuerpo polar es liberado (13).

El ciclo celular meiótico de los oocitos en los mamíferos (excepto los oocitos de los caninos que se detienen en la profase de la meiosis I) se bloquea en la metafase II de la meiosis después de la ovulación y el ciclo se reinicia después de la fecundación, debido a la presencia del factor promotor de la maduración activo (MPF), el cual es un modulador del ciclo celular que está compuesto por las subunidades p34 ${ }^{\mathrm{cdc} 2}$ quinasa y ciclina $B 1$ y, es responsable de inducir el ensamble del huso meiótico, la condensación de la cromatina y la desintegración nuclear (12). Durante el bloqueo de la metafase II, el MPF permanece activo debido a la presencia del factor citostático CFS que está compuesto, al menos en parte, por las proteínas c-mos, MAP quinasa, p90 Rsk y Emi 1, lo cual previene la degradación de la ciclina $B 1(12,15)$.

\section{Maduración del espermatozoide}

Durante la maduración, la mayor parte del citoplasma del espermatozoide es eliminado pero se conservan las vesículas que darán lugar al acroso$\mathrm{ma}$, algunas mitocondrias, la cola y el núcleo, que es rodeado por una estructura del citoesqueleto conocida como teca perinuclear, lo cual es fundamental para la estabilización de las estructuras espermáticas (16). Así, el espermatozoide maduro se compone de: la cabeza que contiene el núcleo con una cromatina altamente condensada y el acrosoma que posee las enzimas necesarias que facilitan la travesía del espermatozoide a través de la zona pelúcida; la pieza intermedia donde se encuentran las mitocondrias, y la cola o la pieza principal que se origina de los centríolos, produciendo el axonema $(17,18)$.

El eyaculado humano está compuesto por el plasma seminal y los espermatozoides. Diferentes estructuras del tracto genital masculino aportan componentes al plasma seminal: la vesícula seminal contribuye con fructosa, aminoácidos, ácido cítrico, fósforo, potasio y hormonas; la próstata aporta ácido cítrico, fosfatos ácidos, calcio, sodio, zinc, potasio, albúmina y enzimas $y$, finalmente las secreciones de las glándulas uretrales y bulbouretrales le proporcionan la contextura espesa, color claro y propiedad lubricante (19).

La integridad del núcleo del espermatozoide humano es fundamental para lograr la fecundación y el adecuado desarrollo embrionario $(20,21)$. La experimentación en animales ha proporcionado evidencia sobre las consecuencias desfavorables en el desarrollo embrionario y en la presentación de enfermedades en la descendencia cuando el ADN presenta algún daño en la línea germinal paterna (3). Aunque este daño puede ocurrir en el testículo, en el epidídimo o después de la eyaculación, los espermatozoides disponen de tres mecanismos protectores: el empaquetamiento del ADN, la apoptosis y los antioxidantes presentes en el plasma seminal para proteger sus estructuras de daño (8).

\section{Empaquetamiento del ADN}

La espermatogénesis es la diferenciación de las células germinales desde espermatogonias a espermatozoides; comienza en la pubertad y es un proceso continuo caracterizado por un estadío premeiótico llamado espermatogoniogénesis, un estadío meiótico y otro postmeiótico o espermiogénesis (22). El empaquetamiento del núcleo espermático ocurre durante la espermiogénesis y es diferente al que ocurre en las células somáticas: la mayoría de las histonas que son las proteínas encargadas del empaquetamiento de la cromatina en las células somáticas, son removidas y sustituidas con proteínas de transición (TP1 y TP2), las cuales son reemplazadas posteriormente por proteínas nucleares denominadas protaminas (P1 y $P 2)(17,23,24)$. Adicionalmente, en este estadío y en la maduración epididimal se forman puentes disulfuro entre estos residuos proteicos, haciendo al ADN unas seis veces más compacto, con un volumen 40 veces menor que el de una célula somática, lo que implica un espermatozoide transcripcionalmente inactivo; este empaquetamiento le permite al núcleo espermático tener una estabilidad adicional que es necesaria para asegurar el transporte y la integridad del material genético masculino durante su desplazamiento en el tracto reproductivo femenino $(24,25)$.

En los mamíferos, el núcleo del espermatozoide completamente maduro es muy resistente a tratamiento químico y a estrés físico, debido a las uniones cruzadas por puentes disulfuro de las protaminas nucleares. Cuando los espermatozoides se someten a congelación y descongelación, sin crioprotección, se altera la integridad de las membranas plasmáticas y de otras estructuras, pero el núcleo espermático mantiene las propiedades esenciales para dar comienzo al desarrollo embrionario, lo que se demuestra por inoculación de estos espermatozoides alterados en el oocito (26).

\section{Mecanismo de la apoptosis}

Una de las vías involucradas en la apoptosis de los espermatozoides es la de Fas-Fas ligando; las 
células de Sertoli expresan Fas ligando y señalan la destrucción de células germinales Fas positivas limitando, de esta manera, el tamaño de la población celular germinal a un número que ellas pueden soportar $(27,28)$.

Los espermatozoides con fragmentación en las cadenas de ADN son normalmente eliminados durante la espermatogénesis, como un mecanismo de control, pero pueden persistir en el eyaculado debido a una falla en el proceso de apoptosis, lo que podría resultar en una fecundación con desarrollo embrionario anormal y posterior muerte del embrión (29).

\section{Antioxidantes en el plasma seminal}

En andrología básica se ha dado gran importancia a las especies reactivas del oxígeno (ERO) como fuente de alteración de la integridad de la membrana y del ADN en el espermatozoide. Las ERO son agentes de oxidación altamente reactivas que actúan sobre lípidos, amino ácidos y carbohidratos y pueden causar mutaciones en el ADN, debido a que las bases y las columnas fosfodiéster de este último son muy susceptibles a la peroxidación (30). Las fuentes principales de las ERO en los eyaculados humanos son los leucocitos y los espermatozoides morfológicamente anormales, o espermatozoides sometidos a condiciones de isquemia o hipoxia cuando se presentan alteraciones vasculares en el tracto reproductivo masculino $(30,31)$.

La membrana plasmática del espermatozoide en los mamíferos presenta una composición lipídica altamente específica con un alto contenido de ácidos grasos poliinsaturados, plasmalógenos y esfingomielinas; esta estructura es responsable de la flexibilidad y de la capacidad funcional de los espermatozoides pero constituye el principal sustrato para la peroxidación, lo cual puede dar lugar a severos desórdenes funcionales en el espermatozoide $(30,31)$. De hecho, los espermatozoides tienen niveles despreciables de antioxidantes debido probablemente a su poco contenido de citoplasma (32), haciéndolos incapaces de reparar el daño inducido por las ERO ya que pierden los sistemas enzimáticos citoplasmáticos que se requieren para cumplir con esta reparación, y por este motivo son únicos en su susceptibilidad a la ofensa oxidativa $(24,33)$. Afortunadamente, en el plasma seminal existen antioxidantes tanto de sistemas enzimáticos como no enzimáticos, entre los que se encuentran: glutatión, superóxido dismutasa, catalasa, glutatión peroxidasa, glutatión reductasa, $\alpha$ tocofenol, $\beta$-caroteno, ascorbato, urato, transferrina, lactoferrina, vitaminas $\mathrm{E}$ y $\mathrm{C}$ y ácidos mercaptúricos como taurina e hipotaurina, que protegen al esper- matozoide frente a la ofensa oxidativa $(17,30,31$, 34).

La capacidad antioxidante del plasma seminal parece ser un buen indicador para determinar la etiología de la infertilidad masculina y potencialmente, la aparición de mutaciones en la línea germinal a partir de espermatozoides con daño del ADN (30). Incluso, el lavado de los espermatozoides y la subsiguiente remoción del plasma seminal elimina el potencial protector suministrado por éste; esta situación puede agravarse si las células son lavadas y resuspendidas en soluciones contaminadas con metales de transición, que aumentan la producción de las ERO y la generación de fracturas en el ADN (35).

En condiciones fisiológicas, en el tracto reproductivo masculino se presenta un balance entre la generación de las ERO y los mecanismos antioxidantes del plasma seminal y sólo permanece la cantidad mínima de las ERO necesaria para regular algunas funciones de los espermatozoides como la capacitación espermática, la reacción acrosomal y la fusión espermatozoide-oocito $(36,37)$. Sin embargo, la producción excesiva de las ERO, lo cual está relacionado con anormalidades del tracto reproductivo masculino, puede alterar todas las estrategias de defensa antioxidante del plasma seminal cuando éstas exceden los niveles críticos, causando un estado de desbalance oxidativo y la subsiguiente lipoperoxidación de la membrana plasmática de los espermatozoides, como también un incremento significativo en el daño del ADN, tales como fraccionamiento de cadena sencilla y doble, modificación de bases, producción de sitios libres de base, delecciones, cambios en el marco de lectura, uniones cruzadas y rearreglos cromosómicos (34, 38-40).

En el núcleo del espermatozoide persiste algún nivel de reparación del ADN, pero las lesiones de cadena simple que finalmente permanezcan en el espermatozoide, deben ser reparadas en el oocito fecundado y de esta manera no deberían ser letales. Sin embargo, si el espermatozoide que fecunda tiene fracturas de tamaño significativo en cualquiera de las dos cadenas del ADN, puede ser difícil para el oocito repararlo, conduciendo a posibles fallas en el desarrollo embrionario preimplantatorio, interrupción de la gestación y un incremento en la morbilidad de la descendencia $(21,30,40)$.

\section{Fusión espermatozoide-oocito}

La fecundación requiere de una secuencia coordinada de eventos entre el espermatozoide y el oocito para formar un zigoto y posteriormente un 
nuevo individuo. Así, los procesos que debe sufrir el espermatozoide para poder fecundar al oocito e iniciar el desarrollo son: capacitación espermática, unión específica del espermatozoide con el acrosoma intacto a la zona pelúcida, reacción acrosomal o exocitosis celular del espermatozoide, paso a través de la membrana extracelular del oocito, penetración al espacio perivitelino, fusión del espermatozoide con la membrana plasmática del oocito, y aporte de los componentes celulares espermáticos para el inicio de la división celular del zigoto $(18,41)$.

Después de la fusión del espermatozoide a la membrana del oocito, la envoltura nuclear espermática se desintegra, la teca perinuclear que rodea el núcleo es removida y la cromatina sufre un proceso de descondensación. Esta última se inicia en la región posterior y progresa hasta la porción anterior de la cabeza del espermatozoide con la reducción de las uniones disulfuro por la presencia de glutation reducido en el citoplasma del oocito y la sustitución de las protaminas por histonas derivadas del mismo (42, 43).

La cola del espermatozoide también entra al oocito y las mitocondrias espermáticas se disocian de la pieza media pero permanecen juntas y en agregados en el citoplasma del oocito (44); sin embargo sufren destrucción mediada por proteasoma debido a que las proteínas mitocondriales son marcadas durante la espermatogénesis con ubiquitina (45). De esta manera, las mitocondrias paternas no persisten más allá del estadío de preimplantación embrionaria y sólo las de origen materno son heredadas (46).

En la mayoría de los mamíferos, excepto en los ratones, el centríolo espermático es el responsable de la organización del áster espermático dentro del citoplasma del oocito, una estructura de microtúbulos que se requiere para la generación de la cadena microtubular que es importante en la migración pronuclear (5). Finalmente, la mayoría de los elementos estructurales restantes de la cola espermática desaparecen rápidamente después de la incorporación en el oocito (44).

\section{Activación del oocito en los mamíferos}

Durante la fecundación, la unión del espermatozoide a la membrana plasmática del oocito induce la liberación de calcio intracelular en el oocito, lo cual interrumpe el bloqueo en la metafase II de la meiosis, debido a que se pierde la actividad del factor citostático CFS, haciendo que el factor MPF se inactive y ocasione la degradación de la ciclina B 1 y de c-mos mediada por el proteasoma; el anterior evento ocurre simultáneamente con la descondensación de la cromatina espermática en el citoplasma del oocito $(13,47,48)$.

El ciclo celular es controlado por un balance de las actividades quinasas y fosfatasas que modulan la actividad de las proteínas celulares y los cambios morfológicos observados durante la reanudación meiótica que incluyen rotación del huso metafásico (en algunas especies), entrada a la anafase y liberación del segundo cuerpo polar, lo cual hace que el genoma originado del gameto femenino se convierta en haploide $(13,48)$.

En los mamíferos, la concentración de calcio intracelular oscila repetidamente por un período que puede durar varias horas después de la fusión espermatozoide-oocito (49). Las elevaciones en el calcio intracelular causan la exocitosis de gránulos que se localizan en la región cortical del oocito debajo de la membrana plasmática, los cuales contienen enzimas que se liberan en el espacio perivitelino, dando origen a modificaciones de la zona pelúcida del oocito que previenen la unión y la penetración de espermatozoides adicionales a la misma (48).

Otra proteína quinasa importante en la regulación del ciclo celular meiótico es la MAP quinasa, la cual fosforila proteínas cromosómicas importantes para mantener a la cromatina en un estado condensado durante la transición de meiosis I a meiosis II y prevenir la formación de la envoltura nuclear por la fosforilación de las láminas nucleares (50). Durante la activación del oocito, la actividad de la MAP quinasa comienza a disminuir después de la reducción de la actividad del factor MPF y esta disminución se requiere antes que ocurra la formación de la envoltura pronuclear (50).

Los principales cambios en el patrón de síntesis de proteínas ocurren durante la activación del oocito y se originan en parte por el reclutamiento de los mARN maternos que están presentes en el citoplasma del oocito pero que no traducen antes de la activación del mismo y por otra parte, por las modificaciones postraduccionales de proteínas existentes (48).

\section{Formación pronuclear y primera división mitótica del embrión}

Varias horas después de la fusión del espermatozoide al oocito cesan las oscilaciones de calcio, el pronúcleo femenino comienza a formarse y la cabeza espermática se descondensa formando el pronúcleo masculino (13). Debido a que el áster 
crece desde el centrómero masculino para capturar y arrastrar juntos a los pronúcleos masculino y femenino, el pronúcleo masculino rota sobre el femenino para alinear la cromatina en el huso que se formará entre ambos pronúcleos, lo cual asegurará que todos los cromosomas estén sobre el huso para la siguiente división mitótica (13).

Después del alineamiento de los pronúcleos, las membranas nucleares se desintegran y el huso rota de manera perpendicular al eje definido por el segundo cuerpo polar, donde la posición de este último, define el plano de división o el eje polar del embrión murino $(48,51)$; la cromatina se condensa en los cromosomas que se organizan sobre un huso mitótico común para dar comienzo a la primera división mitótica, produciendo un embrión de dos células 112 , $13,48)$. Finalmente, ocurre un proceso denominado activación génica del cigoto, que comienza con la transcripción y la traducción de proteínas codificadas por el genoma embrionario recién formado en el estadío de una célula en los murinos y más adelante, durante el desarrollo embrionario preimplantatorio, en los humanos (48).

Es posible que muchos de los eventos anteriormente mencionados no se lleven a cabo adecuadamente cuando se presentan alteraciones epigenéticas en el espermatozoide. Sobre esta base, a continuación se describirá la influencia que podría tener el gameto masculino en la muerte embrionaria temprana:

\section{Alteración en el remodelamiento de la cro- matina}

En la compactación subóptima de la cromatina espermática, se han encontrado proporciones alteradas de las protaminas, completa ausencia de las mismas (52) o inapropiada formación de las uniones disulfuro debido a una inadecuada oxidación de tioles en estos residuos proteicos y por lo tanto, durante el tránsito epididimal de los espermatozoides, el ADN sería más vulnerable al daño (53).

En la espermiogénesis, las $P 1$ sufren modificaciones postraduccionales limitadas y las P2 son el resultado de un procesamiento proteolítico de un precursor más grande (54). La haploinsuficiencia causada por la alteración de un alelo de las P1 o P2 produce una cantidad reducida de la proteína respectiva, procesamiento anormal de la P2 y previene la transmisión genética del alelo mutante y del silvestre (53). El uso de espermatozoides deficientes para la P2 en reproducción asistida mediante la inyección intracitoplasmática de espermatozoides
(ICSI) a oocitos murinos en metafase II, mostró que la mayoría de los oocitos se reactivaron, pero sólo unos pocos fueron capaces de desarrollarse hasta el estadío de blastocisto (9). De acuerdo a estos resultados, la P2 podría ser esencial para el mantenimiento de la integridad de la cromatina del espermatozoide y como consecuencia del desarrollo embrionario temprano.

De otro lado, los ratones nulos para los genes que codifican las proteínas de transición, TP1 (55) o TP2 (56) son infértiles con un procesamiento anormal de la P2 y una condensación nuclear insuficiente. Shirley y colaboradores, observaron que la tasa de fecundación fue tres veces menor comparada con los ratones silvestres y que pocos embriones preimplantados se desarrollaron hasta el estadío de mórula-blastocisto (57).

\section{Errores en la impronta}

El mecanismo de la impronta reside en la modificación epigenética diferencial de secuencias que regulan la expresión de genes específicos en el espermatozoide y en el oocito para originar una sola copia heredada del gen improntado para su expresión en el embrión. Las copias parentales de las regiones improntadas difieren con respecto a la metilación del ADN, la modificación de las histonas y como consecuencia en la expresión génica. Es decir, para los genes improntados paternalmente, el alelo paterno es epigenéticamente modificado para prevenir la transcripción, asegurando que el embrión tenga sólo una expresión monoalélica de la copia heredada de la madre; lo opuesto es lo que sucede con los genes improntados maternalmente, cuando se expresa sólo la copia heredada del padre (58).

La impronta genómica (al menos la metilación del ADN) se establece durante la gametogénesis. Después de la fecundación, durante el desarrollo embrionario temprano, las improntas parentales se borran en las células germinales primordiales y se restablecen durante la gametogénesis masculina y femenina (59).

El genoma paterno en los murinos es significativa y activamente demetilado a las 6-8 horas después de la fecundación, antes del comienzo de la replicación del ADN, mientras que el genoma materno es demetilado después de varias divisiones celulares (60). Esta activa demetilación del genoma paterno puede estar asociada con el remodelamiento epigenético de la cromatina del espermatozoide para establecer programas del desarrollo paterno-específicos durante la embriogénesis temprana (60). 
El hecho que genes particulares sean diferencialmente expresados, de acuerdo a su origen parental, significa que durante el desarrollo, los genomas parentales no son funcionalmente equivalentes (61) y por consiguiente, los errores en la impronta pueden originar un desarrollo anormal, muerte embrionaria o fetal o enfermedades en la descendencia después del nacimiento (62). Cerca de 100 genes en los gametos masculino y femenino de mamíferos, podrían estar improntados apropiadamente de manera parentalespecífica para permitir un desarrollo embrionario normal. Así, algunos de los genes expresados del padre como PLAGL1 Igen adenoma pleiomórfico tipo 1), PEG1 /MEST (gen 1 expresado paternalmente/ transcripto específico de mesodermo), IGF2 (factor insulinoide de crecimiento tipo II) y PEG3 (gen 3 expresado paternalmente), mejoran el crecimiento fetal y placentario, mientras que los genes expresados de la madre como IGF2R (receptor del factor insulinoide de crecimiento tipo II), GRAB10 (proteína de unión a la microglobulina alfa 2 relacionada con proteína G), H19 (gen H19), CDKN1C (inhibidor de quinasa dependiente de ciclina 1C), TSSC3 (candidato del fragmento génico 4 transferible subcromosómico de supresión de tumor), MASH2 (factor de transcripción básica hélice-asa-hélice) y MEG3 (gen 3 expresado maternalmente), lo restringen. De esta forma por ejemplo, el bajo peso fetal podría ser causado por la pérdida de la expresión paterna de un gen promotor del crecimiento o por la activación alterada de un alelo paterno de un gen que restringe el crecimiento y que está normalmente silenciado (62).

Uno de los mecanismos mejor explicado, por el cual el daño del ADN derivado del padre puede llevar a la pérdida del embarazo podría involucrar la alteración específica de genes que son esenciales para el desarrollo normal de la unidad feto-placentaria (58). El alelo paterno del gen H19, el cual está normalmente metilado y silenciado en la línea germinal paterna, es frecuentemente hipometilado en los casos de infertilidad masculina (7).

La consecuencia anticipada de este evento de hipometilación es la transcripción activa del gen H19 y, como consecuencia, la inactivación del gen materno IGF2 recíprocamente improntado. Debido a que IGF2 está íntimamente involucrado en la placentación, se esperaría que su inactivación altere el desarrollo embrionario (7). Lo anterior se explica ya que en células germinales normales, el sitio de unión a CTCF (proteína dedo de zinc que se une a varios sitios en la región de control improntada sin metilar y es esencial para potenciar el bloqueo) está sin metilar en el cromosoma materno y la unión de CTCF a este sitio promueve la activación del gen $\mathrm{H} 19$ y el silenciamiento del gen IGF2. Por el contrario, en el cromosoma paterno, el sitio de unión a CTCF está metilado, es incapaz de unirse con CTCF y como consecuencia, IGF2 es activado y H19 es silenciado. De esta manera, podría predecirse que la transmisión de un alelo paterno sin metilar conduce a la presencia de dos alelos de IGF2 inactivos y dos alelos de H19 activos en el embrión $y$, por lo tanto, retardo en su desarrollo (63).

Para demostrar si una incorrecta impronta genómica paterna podría estar asociada con la espermatogénesis alterada, Marques y colaboradores extrajeron ADN espermático de 123 muestras de semen de individuos normozoospérmicos y de individuos oligozoospérmicos sometidos a análisis seminal por diagnóstico de infertilidad. Algunos hombres oligozoospérmicos tuvieron espermatozoides con metilación defectuosa del sitio de unión a CTCF entre los genes IGF2 y H19 (7).

\section{Ausencia o alteración del centrosoma esper- mático}

Como anteriormente se mencionó, en muchas especies, el centrosoma proximal llega a ser el centro del áster espermático que dirige al pronúcleo masculino y femenino al centro del cigoto (64). Actualmente, es claro que la formación del huso mitótico en la primera división embrionaria en humanos, depende de los centros de generación de microtúbulos derivados del centrosoma del espermatozoide, ubicado en la cola (10). En un estudio realizado por Moomiy y colaboradores, usando ICSI, observaron que después de inyectar sólo la cabeza espermática en un oocito, se formó un pronúcleo masculino pero las subsiguientes divisiones se caracterizaron generalmente, por varios grados de mosaicismos como consecuencia de una disyunción cromosómica aberrante, sugiriendo que la presencia de la cola o al menos su centrosoma es importante para el desarrollo embrionario normal (10).

Los embriones de espermatozoides con centrosomas pobremente desarrollados, dañados o ausentes podrían presentar niveles variables de desorganización. Esta correlación ha sido demostrada por Rawe y colaboradores en un reporte de caso de un paciente con una forma severa de teratozoospermia caracterizada por una adhesión defectuosa de la cabeza con la pieza media y espermatozoides acefálicos, además de inmovilidad total; adicionalmente, los espermatozoides del paciente presentaron una morfología centromérica alterada y una capacidad reducida para formar ásteres espermáticos. En el intento de fecundación con ICSI, el cigoto no progresó más allá del estadío pronuclear del desarrollo em- 
brionario, lo que sugirió un defecto de origen paterno más que materno, ya que en humanos el centríolo dentro del centrosoma cigótico naciente se deriva de los espermatozoides. Cuando en paralelo se inyectaron espermatozoides de un donante fértil, se observó un claro contraste con la obtención de un alto porcentaje de ásteres espermáticos completamente desarrollados (65).

Por estas evidencias, los autores sugieren que el centríolo espermático es esencial para la fecundación exitosa, mientras que sólo las alteraciones en la cola que impiden la movilidad espermática no tienen un papel significativo en este evento. Este hallazgo enfatiza a) la necesidad de una evaluación morfológica cuidadosa de los espermatozoides para entender mejor la fisiología de la fecundación normal $y$, eventualmente, trabajar en herramientas pronósticas en reproducción asistida y b) estudiar más a fondo la composición y el funcionamiento del centrosoma espermático para obtener más información acerca de las posibles causas o consecuencias de su anormalidad en el espermatozoide y en el desarrollo del embrión.

\section{Acortamiento telomérico}

Se ha sugerido que sólo los espermatozoides con un tamaño telomérico suficiente progresan a través de la espermatogénesis (66). En un estudio realizado por Hermann y colaboradores, se encontró una concentración espermática severamente reducida en la tercera generación de ratones provenientes de progenitores que carecían del componente de ARN de la telomerasa (66).

En contraste al estudio anterior, Liu y colaboradores, reportaron espermatocitos en profase I de ratones nulos para la actividad de la telomerasa que poseían telómeros acortados y localización anormal, que probablemente estaban contribuyendo al total de los espermatozoides maduros. Cuando los oocitos silvestres se inseminaron con espermatozoides de estos ratones nulos para la telomerasa se produjo disminución en la fecundación y en la formación de blastocistos, e incremento de fragmentación y apoptosis embrionarias (1 1).

Los anteriores estudios $(11,66)$ proponen que aunque las células germinales en mamíferos con telómeros acortados son destruidas tempranamente en el desarrollo, algunos espermatozoides completan la maduración, lo cual sugiere que el presunto punto de control está alterado en los espermatocitos, y los espermatozoides maduros resultantes podrían ser disfuncionales como resultado del acortamiento telomérico.

\section{Ausencia de RNA espermático}

Existe controversia acerca de la contribución de los ARN espermáticos al desarrollo embrionario. En un estudio realizado por Ostermeier y colaboradores evaluaron el papel de ciertos transcriptos espermáticos tanto en la fecundación como en el desarrollo cigoto-embrionario, usando RT-PCR para determinar cuál de estos transcriptos estaba presente en los espermatozoides humanos pero no en el oocito en metafase II sin fecundar. Encontraron que durante la fecundación, el mARN paterno es depositado en el oocito y que el espermatozoide maduro contiene $m A R N$ que codifica proteínas requeridas para la embriogénesis temprana que están ausentes en el oocito sin fecundar, lo cual hace inferir que el oocito fecundado podría usar estos transcriptos en la fase inicial del desarrollo embrionario (6). Los autores identificaron seis candidatos: clusterina, AKAP4 y Protamina2, liberados en el proceso de la fecundación; HSBP 1 (CDH13) en respuesta a estrés; FOXG1B y WNT5A, implicados en embriogénesis y morfogénesis (6). FOXG $1 B$ es un miembro de los factores de transcripción que contiene un dominio "forkhead" importante en el desarrollo embrionario temprano pero está restringido al cerebro fetal y a los testículos adultos (67). Los homólogos de la familia de WNT5A de moléculas de señalización protooncogénica participan en la diferenciación celular que está asociada con la morfogénesis (68). Así, ambos ARN paternos contribuirían al desarrollo embrionario.

Así mismo, se ha descrito un conjunto de 68 secuencias que podrían tener un papel significativo en el silenciamiento génico a través de ARN de interferencia paterno en el oocito fecundado (69). Los análisis preliminares de estas 68 secuencias mostraron varios blancos potenciales para el mARN en el oocito como DKK2, una proteína en la vía de señalización tipo "wingless", la cual está activa en el desarrollo embrionario. Lo anterior provee evidencia adicional que los transcriptos de mARN paterno son benéficos para la embriogénesis y por lo tanto son preservados, aunque también se ha reportado la presencia de transcriptos paternos deletéreos para el crecimiento embrionario (69).

\section{CONCLUSIONES}

Las contribuciones genéticas del espermatozoide son importantes para la embriogénesis. De hecho, los estudios mencionados en esta revisión sugieren que el daño del $A D N$ en el espermatozoide que fecunda es un factor que influye en cómo un embrión se desarrolla y en cómo el oocito trata de compensar este daño. Sin embargo, no es claro cuánto daño del 
ADN espermático es suficiente para comprometer el desarrollo embrionario, por lo que se requiere cuantificar el deterioro de un espermatozoide individual e identificar un valor umbral de este daño que permita un desarrollo normal, lo cual podría emplearse en técnicas de reproducción asistida. Aunque se ha indicado una fuerte asociación entre el espermatozoide con daño del ADN y una alteración en la embriogénesis, la relación causa-efecto no se ha demostrado aún. Hay que tener en cuenta que el daño del ADN puede ser secundario a otras anormalidades en el espermatozoide y que es poco probable que esta anomalía sea sólo el resultado de errores en el rearreglo de la cromatina o del estrés ambiental.

Como medida preventiva se pudiera promover la reducción del daño del ADN del espermatozoide con el uso de antioxidantes en la dieta y una técnica de selección espermática que permita la separación de espermatozoides con niveles tolerables de deterioro.

Se considera que la organización nuclear en las células somáticas y germinales es una forma de regulación génica-epigenética, aunque se requieren más estudios que se enfoquen en investigar el papel específico de la compactación del ADN espermático en el desarrollo embrionario. Por lo anterior, entre los temas de investigación que serían de gran interés estudiar están:

a) entender mejor cómo la estructura nucleoprotamina-nucleohistona del núcleo del espermatozoide lleva la información epigenética y controla los eventos embrionarios tempranos, tal vez identificando si se requiere la metilación de copias génicas paterno-específicas durante este estadío en el desarrollo y si es así, cuáles podrían ser los genes implicados;

b) determinar si la reducción global en la metilación observada en algunos pacientes (7) es un factor causal de embriogénesis alterada $\circ$ un signo de pobre espermatogénesis que no tiene ningún efecto directo sobre el desarrollo del embrión;

c) investigar la localización de otras regiones específicas del genoma como aquellas que tienen tramos no codificantes de secuencias repetidas o genes improntados con respecto a características específicas de la cromatina;

d) explorar los papeles potenciales de las proteínas de transición en la remoción o degradación de histonas, en la dirección de la incorporación de protaminas, en la interacción con regiones cromosómicas específicas y en el reclutamiento de complejos. Este conocimiento proporcionaría una luz sobre las consecuencias potenciales epigenéticas de la ausencia o la mutación de una o ambas proteínas de transición (TP1 y TP2).

Con respecto al ARN espermático, se ha encontrado que algunos transcriptos específicos identificados en los espermatozoides se correlacionan con la calidad espermática presentada por el individuo, aunque falta identificar si la variación en el contenido de mARN está afectando directamente al espermatozoide maduro o es un indicio de una espermatogénesis anormal (70).

Sería interesante verificar si el espermatozoide que transmite patrones de mARN alterados produce embriones con un potencial disminuido en el desarrollo y demostrar si el mARN transmitido que codifica o interfiere, tiene actividad en el embrión.

El tema desarrollado en esta revisión es importante para tratar de entender el posible papel que tiene el factor masculino en las muertes embrionarias tempranas, lo cual no se tiene en cuenta de una manera significativa por la relación existente entre la mujer y el embrión en desarrollo.

Este conocimiento proporcionaría algunas bases para el tratamiento de diversas alteraciones reproductivas presentadas por los hombres no sólo implicadas con la infertilidad sino también con las pérdidas gestacionales, producidas tal vez, por daño del ADN o alteraciones en la regulación génica-epigenética del espermatozoide ocasionados por ofensa oxidativa, alteración en el remodelamiento de la cromatina o por cualquiera otra causa aún no definida.

Finalmente, la información encontrada en la literatura y las nuevas investigaciones ayudarán en el diagnóstico de alteraciones espermáticas y en la implementación de nuevas estrategias en el manejo de técnicas de reproducción asistida; sin embargo, todavía falta mucho por investigar acerca de las posibles causas de origen paterno implicadas en la muerte embrionaria temprana. Ahora, el compromiso radica en fortalecer este conocimiento y de esta manera, lograr un mayor acercamiento en el entendimiento y posible tratamiento a esta situación que aqueja a una cantidad significativa de parejas en el mundo.

\section{AGRADECIMIENTOS}

Este trabajo fue financiado por la Universidad de Antioquía (CODI). WCW es becario de COLCIENCIAS. 


\section{BIBLIOGRAFÍA y LECTURAS RECOMENDADAS (*lectura de interés $y^{* *}$ lectura fundamental)}

1. KUTTEH, W.H.: "Recurrent pregnancy loss: An update". Curr. Opin. Obstet. Gynecol., 11: 435, 1999.

2. IRVINE, D.S.: "Epidemiology and aetiology of male infertility". Hum. Reprod., 1: 33, 1998.

*3. AHMADI, A.; NG, S.C.: "Developmental capacity of damaged spermatozoa". Hum. Reprod., 14: 2279, 1999.

4. CARRELL, D.T.; WILCOX, A.L.; LOWY, L. y cols.: "Elevated sperm chromosome aneuploidy and apoptosis in patients with unexplained recurrent pregnancy loss". Obstet. Gynecol., 101: 1229, 2003.

*5. SCHATTEN, G.: "The centrosome and its mode of inheritance: The reduction of the centrosome during gametogenesis and its restoration during fertilization". Dev. Biol., 165: 299, 1994.

*6. OSTERMEIER, G.C.; MILLER, D.; HUNTRISS, J.D. y cols.: "Reproductive biology: Delivering spermatozoan RNA to the oocyte". Nature., 429: $154,2004$.

7. MARQUES, C.J.; CARVALHO, F.; SOUSA, M. y cols.: "Genomic imprinting in disruptive spermatogenesis". Lancet., 363: 1700, 2004.

8. LEWIS, S.E.; AITKEN, R.J.: "DNA damage to spermatozoa has impacts on fertilization and pregnancy". Cell. Tissue. Res., 322: 33, 2005.

9. CHO, C.; JUNG-HA, H.; WILLIS, W.D. y cols.: "Protamine 2 deficiency leads to sperm DNA damage and embryo death in mice". Biol. Reprod., 69: 211, 2003.

*10. MOOMJY, M.; COLOMBERO, L.T.; VEECK, L.L. y cols.: "Sperm integrity is critical for normal mitotic division and early embryonic development". Mol. Hum. Reprod., 5: 836, 1999.

11. LIU, L.; BLASCO, M.; TRIMARCHI, J. y cols.: "An essential role for functional telomeres in mouse germ cells during fertilization and early development". Dev. Biol., 249: 74, 2002.

12. ALBERIO, R.; ZAKHARTCHENKO, V.; MOTLIK, J. y cols.: "Mammalian oocyte activation: Lessons from the sperm and implications for nuclear transfer". Int. J. Dev. Biol., 45: 797, 2001.

**13. SCOTT, L.: "The biological basis of non-invasive strategies for selection of human oocytes and embryos". Hum. Reprod. Update., 9: 237, 2003.

14. VERLHAC, M.H.; LEFEBVRE, C.; GUILLAUD, P. y cols.: "Asymmetric division in mouse oocytes: With or without Mos". Curr. Biol., 10: $1303,2000$.

15. REIMANN, J.D.; JACKSON, P.K.: "Emi1 is required for cytostatic factor arrest in vertebrate eggs". Nature., 416: 850, 2002.
16. RAMALHO-SANTOS, J.; SCHATTEN, G.; MORENO, R.D.: "Control of membrane fusion during spermiogenesis and the acrosome reaction". Biol. Reprod., 67: 1043, 2002.

**17. YANAGIMACHI, R.: "Fertilization in mammalian, in the physiology of reproduction". (N. J. Knobil E, Ed.), Raven Press Ltd., New York, pp.189, 1994.

*18. CARDONA MAYA, W.D.; CADAVID JARAMILLO, A.P.: "Interacción intergametos: Breve revision”. Arch. Esp. Urol., 57: 1107, 2004.

19. OWEN, D.H.; KATZ, D.F.: "A review of the physical and chemical properties of human semen and the formulation of a semen stimulant". J. Androl., 26: 459, 2005.

20. GOPALKRISHNAN, K.; HURKADLI, K.; PADWAL, V. y cols.: "Use of acridine orange to evaluate chromatin integrity of human spermatozoa in different groups of infertile men". Andrologia., 31: 277, 1999.

*21. CARRELL, D.T.; LIU, L.; PETERSON, C.M. y cols.: "Sperm DNA fragmentation is increased in couples with unexplained recurrent pregnancy loss". Arch. Androl., 49: 49, 2003.

22. HOLSTEIN, A.F.; SCHULZE, W.; DAVIDOFF, M.: "Understanding spermatogenesis is a prerequisite for treatment". Reprod. Biol. Endocrinol., 1: $107,2003$.

23. FUENTES-MASCORRO, G.; SERRANO, H.; ROSADO, A.: "Sperm chromatin". Arch. Androl., 45: 215, 2000.

**24. AGARWAL, A.: "Significance of oxidative stress and sperm chromatin damage in male infertility". Male Fertility and Lipid Metabolism. (Editors: S. De Vriese and A. Christophe), AOCS Press, Champaign, IL, Chapter 13: pp. 157, 2003.

25. WYKES, S.M.; VISSCHER, D.W.; KRAWETZ, S.A.: "Haploid transcripts persist in mature human spermatozoa". Mol. Hum. Reprod., 3: 15, 1997.

26. KANEKO, T.; WHITTINGHAM, D.G.; OVERSTREET, J.W. y cols.: "Tolerance of the mouse sperm nuclei to freeze-drying depends on their disulfide status". Biol. Reprod., 69: 1859, 2003.

27. RODRIGUEZ, I.; ODY, C.; ARAKI, K. y cols.: "An early and massive wave of germinal cell apoptosis is required for the development of functional spermatogenesis". Embo. J., 16: 2262, 1997.

28. PENTIKAINEN, V.; ERKKILA, K.; DUNKEL, L.: "Fas regulates germ cell apoptosis in the human testis in vitro". Am. J. Physiol., 276: 310, 1999.

29. SAKKAS, D.; MARIETHOZ, E.; ST JOHN, J.C.: "Abnormal sperm parameters in humans are indicative of an abortive apoptotic mechanism linked to the Fas-mediated pathway". Exp. Cell. Res., 251: 350, 1999 . 
30. AGARWAL, A.; SAID, T.M.: "Role of sperm chromatin abnormalities and DNA damage in male infertility". Hum. Reprod. Update, 9: 331, 2003.

*31. SANOCKA, D.; KURPISZ, M.: "Reactive oxygen species and sperm cells". Reprod. Biol. Endocrinol., 2: 12, 2004.

32. AITKEN, R.J.; FISHER, H.M.; FULTON, N. y cols.: "Reactive oxygen species generation by human spermatozoa is induced by exogenous NADPH and inhibited by the flavoprotein inhibitors diphenylene iodonium and quinacrine". Mol. Reprod. Dev., 47: 468, 1997.

33. AITKEN, J.; FISHER, H.: "Reactive oxygen species generation and human spermatozoa: The balance of benefit and risk". Bioessays, 16: 259, 1994.

34. TWIGG, J.; FULTON, N.; GOMEZ, E. y cols.: "Analysis of the impact of intracellular reactive oxygen species generation on the structural and functional integrity of human spermatozoa: Lipid peroxidation, DNA fragmentation and effectiveness of antioxidants". Hum. Reprod., 13: 1429, 1998.

35. POTTS, R.J.; NOTARIANNI, L.J.; JEFFERIES, T.M.: "Seminal plasma reduces exogenous oxidative damage to human sperm, determined by the measurement of DNA strand breaks and lipid peroxidation". Mutat. Res., 447: 249, 2000.

36. GRIVEAU, J.F.; LE LANNOU, D.: "Reactive oxygen species and human spermatozoa: Physiology and pathology". Int. J. Androl., 20: 61, 1997.

37. AITKEN, R.J.; GORDON, E.; HARKISS, D. y cols.: "Relative impact of oxidative stress on the functional competence and genomic integrity of human spermatozoa". Biol. Reprod., 59: 1037, 1998.

38. FRAGA, C.G.; MOTCHNIK, P.A.; WYROBEK, A.J. y cols.: "Smoking and low antioxidant levels increase oxidative damage to sperm DNA". Mutat. Res., 351: 199, 1996.

39. SUN, J.G.; JURISICOVA, A.; CASPER, R.F.: "Detection of deoxyribonucleic acid fragmentation in human sperm: Correlation with fertilization in vitro". Biol. Reprod., 56: 602, 1997.

40. AITKEN, R.J.; KRAUSZ, C.: "Oxidative stress, DNA damage and the Y chromosome". Reproduction, 122: 497, 2001.

41. WASSARMAN, P.M.: "Profile of a mammalian sperm receptor". Development, 108: 1, 1990.

42. SUTOVSKY, P.; SCHATTEN, G.: "Depletion of glutathione during bovine oocyte maturation reversibly blocks the decondensation of the male pronucleus and pronuclear apposition during fertilization". Biol. Reprod., 56: 1503, 1997.
43. TERADA, Y.; LUETJENS, C.M.; SUTOVSKY, P. y cols.: "Atypical decondensation of the sperm nucleus, delayed replication of the male genome, and sex chromosome positioning following intracytoplasmic human sperm injection (ICSI) into golden hamster eggs: Does ICSI itself introduce chromosomal anomalies?". Fertil. Steril, 74: 454, 2000.

44. SUTOVSKY, P.; NAVARA, C.S.; SCHATTEN, G.: "Fate of the sperm mitochondria, and the incorporation, conversion, and disassembly of the sperm tail structures during bovine fertilization". Biol. Reprod., 55: 1195, 1996.

**45. SUTOVSKY, P.; SCHATTEN, G.: "Paternal contributions to the mammalian zygote: Fertilization after sperm-egg fusion”. Int. Rev. Cytol., 195: 1, 2000.

*46. CUMMINS, J.M.; WAKAYAMA, T.; YANAGIMACHI, R.: "Fate of microinjected sperm components in the mouse oocyte and embryo". Zygote, 5: 301, 1997.

47. JONES, K.T.: "Mammalian egg activation: from $\mathrm{Ca} 2+$ spiking to cell cycle progression". Reproduction, 130: 813, 2005.

*48. WILLIAMS, C.J.: "Signalling mechanisms of mammalian oocyte activation". Hum. Reprod. Update, 8: 313, 2002.

49. MIYAZAKI, S.; SHIRAKAWA, H.; NAKADA, K. y cols.: "Essential role of the inositol 1,4,5trisphosphate receptor/Ca2+ release channel in $\mathrm{Ca} 2+$ waves and $\mathrm{Ca} 2+$ oscillations at fertilization of mammalian eggs". Dev. Biol., 158: 62, 1993.

50. MOOS, J.; VISCONTI, P.E.; MOORE, G.D. y cols.: "Potential role of mitogen-activated protein kinase in pronuclear envelope assembly and disassembly following fertilization of mouse eggs". Biol. Reprod, 53: 692, 1995.

51. PIOTROWSKA, K.; ZERNICKA-GOETZ, M.: "Role for sperm in spatial patterning of the early mouse embryo". Nature, 409: 517, 2001.

52. DE YEBRA, L.; BALLESCA, J.L.; VANRELL, J.A. y cols.: "Complete selective absence of protamine P2 in humans". J. Biol. Chem., 268: 10553, 1993.

53. CHO, C.; WILLIS, W.D.; GOULDING, E.H. y cols.: "Haploinsufficiency of protamine-1 or -2 causes infertility in mice". Nat. Genet., 28: 82, 2001.

54. WOUTERS-TYROU, D.; MARTINAGE, A.; CHEVAILLIER, P. y cols.: "Nuclear basic proteins in spermiogenesis". Biochimie, 80: 117, 1998.

55. YU, Y.E.; ZHANG, Y.; UNNI, E. y cols.: “Abnormal spermatogenesis and reduced fertility in transition nuclear protein 1-deficient mice". Proc. Natl. Acad. Sci. USA, 97: 4683, 2000. 
56. ZHAO, M.; SHIRLEY, C.R.; YU, Y.E. y cols.: "Targeted disruption of the transition protein 2 gene affects sperm chromatin structure and reduces fertility in mice". Mol. Cell. Biol., 21: 7243, 2001.

57. SHIRLEY, C.R.; HAYASHI, S.; MOUNSEY, S. y cols.: "Abnormalities and reduced reproductive potential of sperm from Tnp1- and Tnp2-null double mutant mice". Biol. Reprod, 71: 1220, 2004.

58. CONSTANCIA, M.; HEMBERGER, M.; HUGHES, J. y cols.: "Placental-specific IGF-II is a major modulator of placental and fetal growth". Nature., 417: 945, 2002.

*59. ROUSSEAUX, S.; CARON, C.; GOVIN, J. y cols.: "Establishment of male-specific epigenetic information". Gene, 345: 139, 2005.

60. MAYER, W.; NIVELEAU, A.; WALTER, J. y cols.: "Demethylation of the zygotic paternal genome". Nature, 403: 501, 2000.

61. SURANI, M.A.: "Imprinting and the initiation of gene silencing in the germ line". Cell, 93: 309, 1998.

62. HORSTHEMKE, B.; LUDWIG, M.: "Assisted reproduction: the epigenetic perspective". Hum. Reprod. Update, 11: 473, 2005.

63. HARK, A.T.; SCHOENHERR, C.J.; KATZ, D.J. y cols.: "CTCF mediates methylation-sensitive enhancer-blocking activity at the H19/Igf2 locus". Nature, 405: 486, 2000.
64. KIM, N.H.; LEE, J.W.; JUN, S.H. y cols.: "Fertilization of porcine oocytes following intracytoplasmic spermatozoon or isolated sperm head injection”. Mol. Reprod. Dev., 51: 436, 1998.

65. RAWE, V.Y.; TERADA, Y.; NAKAMURA, S. y cols.: "A pathology of the sperm centriole responsible for defective sperm aster formation, syngamy and cleavage". Hum. Reprod., 17: 2344, 2002.

66. HEMANN, M.T.; RUDOLPH, K.L.; STRONG, M.A. y cols.: "Telomere dysfunction triggers developmentally regulated germ cell apoptosis". Mol. Biol. Cell, 12: 2023, 2001.

67. MURPHY, D.B.; WIESE, S.; BURFEIND, P. y cols.: "Human brain factor 1, a new member of the fork head gene family". Genomics, 2: 551, 1994.

68. MOON, R.T.; BROWN, J.D.; TORRES, M.: "WNTs modulate cell fate and behavior during vertebrate development". Trends. Genet., 13: 157, 1997.

69. OSTERMEIER, G.C.; GOODRICH, R.J.; MOLDENHAUER, J.S. y cols.: "A suite of novel human spermatozoal RNAs". J. Androl., 26: 70, 2005.

70. LAMBARD, S.; GALERAUD-DENIS, I.; MARTIN, G. y cols.: "Analysis and significance of mRNA in human ejaculated sperm from normozoospermic donors: Relationship to sperm motility and capacitation". Mol. Hum. Reprod., 10: 535, 2004. 